\title{
Product development and project-based learning in Mechatronics, in the context of digitization and sustainability
}

\author{
Mette Mo Jakobsen*1, Sondre Sanden Tørdal ${ }^{\dagger 1}$, Andreas Klausen ${ }^{\ddagger 1}$, \\ Kjell G. Robbersmyr ${ }^{\S}$ and Ilya Tyapin $\$$ \\ ${ }^{1}$ Department of Engineering Sciences, University of Agder, Norway
}

\begin{abstract}
Engineering projects affect many of the UN's sustainability goals. The development and design of new products and systems using a circular economy perspective is an important challenge towards a more sustainable society. Product development projects have common process characteristics, but methodologies, tools and methods differ for developing hardware (mechanical and electrical) or developing software. In Mechatronics such methods need to be combined, and product development and project-based learning is well suited for teaching and learning within Mechatronics, in addition to technical specialization subjects within both mechanical, electrical and software engineering. It is also suited for developing consciousness for sustainability. At Department of Engineering Sciences at UiA project based learning is a part of several courses. This article draw out some experiences from teaching two different project based product development courses the last two years, one at Bachelor and one at Master level. The courses are viewed as products, and product development is used as methodology for developing teaching and learning as well. The aim is continuous improvement of the learning outcome of these courses. This is in accordance with the SoTL-approach, Scholarship of teaching and learning.
\end{abstract}

\section{INTRODUCTION}

Attitudes, values, skills, knowledge and understanding are future competence needs [1], that teaching product development may emphasize. To facilitate competence development that help students do conscious choices, both in their development practice and for the products developed is important. For quality products, different product dimensions and a life-cycle perspective brings up many trade-offs. Up to $80 \%$ of the environmental impacts of products are determined in the development phase [2]. The product specification and concept development lay a large part of the foundation for product quality in the whole product life cycle, related to different product dimensions, i.e. function, production, use, safety, environmental impact, logistics, reverse logistics. In the early stages of product development, only a small part of the total cost of the product/project is used, but a large part of the costs, the quality and the impacts are determined. In subsequent phases, the possibility of influencing both costs and impacts are reduced. Engineering projects affect many of the UN's sustainability goals as well as quality and profitability of business. To prepare students for work it is appropriate to develop their product development skills. This is suitable also to develop their willingness to learn new things, their skills in problem-solving and their teamwork-skills, which is necessary working life competencies $[1,3]$. In this context product development and project-based learning is well suited for teaching and learning within Mechatronics, in addition to technical specialization within both mechanical, electrical and software engineering.

\footnotetext{
*mette.mo.jaboksen@uia.no

†sondre.tordal@uia.no

†andreas.klausen@uia.no

§kjell.g.robbersmyr@uia.no

"ilya.tyapin@uia.no
} 


\section{PRODUCT DEVELOPMENT, PROJECT-BASED LEARNING, TEAMWORK, DIGITIZA- TION AND SUSTAINABILITY IN MECHATRONICS}

Project-based learning and teamwork has been used as a common teaching and learning approach within Mechatronics Engineering for the courses Product Development, elective Bachelor course, fifth semester (MAS105) and Product Development and Project Management on Master level (MAS507). A life-cycle perspective has been the context. In addition the bachelor courses Practical engineering, first semester (MAS133) and Mechatronics Project 1, third semester (MAS238) has involved teamwork and used a team contract fall 2020. Figure 1 shows some important dimensions of product development and projects within Mechatronics, visualized related to these courses. This spiderweb diagram used is also suitable for comparing different products, their product properties, trade-offs between them and is useful for discussions of priorities and visualizing results. An important goal is to involve the students ac-

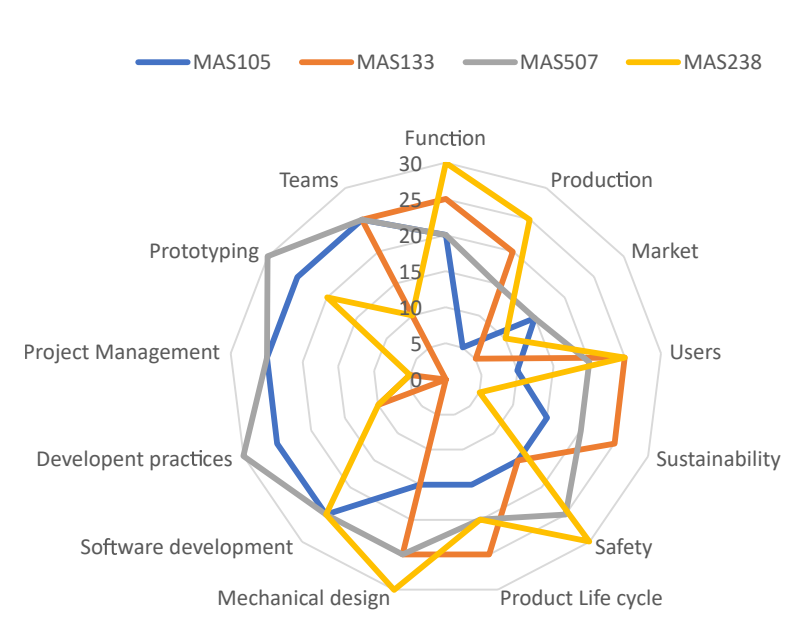

Figure 1: Spiderweb showing dimensions of product development and an estimate of weight in each course. tively in their own learning process by applying theory and producing results, in accordance with the CDIO (conceive, design, implement, operate) approach [4]. For engineers, producing results is a shared goal, and this "getting things done" is a process: it is a way of thinking and doing that involves planning, specification, execution, iteration, and reflection. These are all elements of both product development, project based learning and teamwork. Constructive alignment and assessment for learning is important [5,6]. A typical project-based learning course in this field is assessed based on project report, Mechatronics prototype and presentation. For the product development courses the students were given an overview of expected learning outcome and criteria for evaluation related to these in the beginning of the courses. Typical evaluation criteria:

- Overall impression of the work

- Insight into product development

- The use of digital project planning-, execution-and presentation-tools

- Theoretical insight relevant to the assignment

- Execution, including concept development

- Result (prototype)

- Reflection both on process, result and teamwork

- Presentation (form, structure and content both in digital report and oral presentation)

A case study employing Agile Tools in one of these courses is also further presented and discussed in [7]. Digital tools as Git, GitLab/GitHub, Trello, CI/CD, Scrum, and online documentation using Sphinx ++ are tools supporting active cooperation and teamwork and may increase the quality of learning and relevance within Mechatronics engineering. UNs sustainability goals as well as a life-cycle and circular economy perspective as context for the projects and development processes is suitable to facilitate the student's growth of a competence based on attitudes, values, skills, knowledge and understanding that help them do conscious choices, both in their development practice and for the products developed, as well as for developing their creativity. In knowledge work of all kinds, including product development and software engineering, the creativity and capabilities of people are key competencies [8]. The integration of different areas of expertise in the courses as well as rapid development of software tools is a continuous challenge in both teaching and learning Mechatronics.

\section{TEAMWORK BASED ON A TEAM CONTRACT}

The development of new products and systems using a life-cycle/circular economy perspective is an important challenge towards a more sustainable society. Within Mechatronic engineering it is necessary 
to integrate mechanical, electrical and software engineering. Some tasks are difficult, if not impossible to solve without a team doing the job. Development of mechatronic products is such a task. Using a team-contract makes the team-members more responsible for the teamwork and their common learning outcome. This was expressed by students in their oral examination. For both agile methods, widely used within the software development world, and the many design, engineering and software development methodologies in use, collaboration and teamwork towards shared goals are common characteristics [8]. Agreeing on a team contract was included as a learning activity. In each course, the students got a template for a contract, but they also had to specify their own wishes and requirements for the teamwork, their expected learning outcome and skills:

- First each team-member reflect, fill out and supplement the form individually

- The students fill in own goals for their expected learning outcome as well as their skills

- The competence mapping, learning outcome goals, team and project expectations for the individual team member is then commonly discussed and the form is developed in the team to form a basis for planning of and cooperation in the project

- The team agree on and sign the contract

The weight put on the team contract varied in the courses. For all courses they were given a template for a team contract adapted the specific course, and they were encouraged to use it. They were also expected to reflect on the teamwork in the report and presentation. Using a team contract was confirmed valuable by the teams.

\section{DESIGN FOR LEARNING}

A scholarship of teaching and learning (SoTL) model for developing pedagogical competence is described by Olsson \& Roxå [9]. A fundamental model for a product improvement process is often called "Design for X". Typical activities include analysis to gain understanding, diagnosis to identify problems or improvement potential, advice on what should be done to improve the identified problems, change which include developing new solutions, and finally the choice of a new improved product or solution. The $\mathrm{X}$ can represent different requirements or goals, like design for sustainability. X could also be learning, as in design for learning, as the design for $\mathrm{X}$ approach like the SoTL approach has development through knowledge based continuous improvement as the goal. Product development, project-based learning, teamwork, digitization and sustainability in Mechatronics is developed by a design for learning approach.

\section{A PRODUCT DEVELOPMENT APPROACH}

As mentioned earlier, Mechatronics integrate mechanical, electrical and software engineering. Changes from linear to iterative to integrated to continuous integration and continuous deployment and to a lifecycle development process, (e.g. in $[8,10])$ is often seen. Different practices from the different fields have some common characteristics. Common for many approaches is project based working. The strategic dimension of projects concerns creating value. Common characteristics of product development projects can be found, and an iterative process on many levels is necessary:

- To identify needs, customers, users and/or stakeholders.

- To map/investigate/research the issue/task.

- To plan and specify what we want.

- To create alternative solutions at many levels.

- To examine and evaluate the characteristics of solutions, related to the specification.

- To choose/select the best solutions.

- To develop and realize the chosen solution.

This "product development approach" has been effective for teaching and learning Mechatronics, and teamwork is a fundamental way of working. Learning new theory, and apply this within the project, is a part of the learning outcome that also gives students the possibility to make their own priorities, as well as it lets the teachers take new tools and methods into the course, and thus keep up with the fast development, especially related to digital tools and methods. Many methods may be used, and learning and choosing appropriate methods is a part of the learning process. The "product development approach" 
is expected to be suitable for teaching and learning within both other STEM-fields as well as for active learning within many other fields in higher education. This teaching and learning approach has a high potential of stimulating discussions about teaching and learning among teachers involved, as specialists from different fields are typically cooperating.Collaboration on a subject with different knowledge and experience backgrounds contributes to valuable learning, also for the teachers, and gives students a subject with better quality and learning outcomes. The experience from collaboration on teaching these courses is better course quality, dual competence development and improved students results.

\section{EXPERIENCES AND DISCUSSIONS}

This article has presented an approach to teaching and learning based on product development and project-based learning in Mechatronics. The development of a sustainable attitude, creativity, cooperation and teamwork-skills, in addition to knowledge and application of methodology and methods suitable in Mechatronics projects, has been a goal. Using design for learning, the outcome of the courses has been analyzed to gain understanding, and to identify problems or improvement potential. In product development, evaluation is done with different levels of detailing, from screening to evaluation matrices without and with weighing criteria, to prototype development and testing. The need for detailed knowledge is crucial for what to choose, as a thorough evaluation and testing is time consuming and expensive. In this case a qualitative approach with screening has been chosen. Additionally, the midterm course evaluations have been used. There has also been asked for feedback within lessons in class. There is obvious improvement potential which makes a more structured evaluation less appropriate at this point. A case with changes in methodology in one of the courses is described separately in [7]. Further results are presented and discussed below. Students' knowledge of a product development approach is also discussed based on achievement in Bachelors and Master projects. There are several textbooks in product development, often with their origin in different fields. Many are very detailed in terms of procedure and how simple product development tasks should be solved, i.e. they may not be completely suitable for all types of product development. Some are very detailed regarding the initial phases and up to the development of concepts, but do not take the development all the way to the final product. Experiences from product development projects on Bachelor and Master projects in Mechatronics summarized:

1) Product specification: Several students do not see the need and necessity of preparing the specification and that the specification is dynamic and can/should be changed and detailed as the project progresses, and decisions are taken. 2) Concept selection: Problematic if two concepts are almost equal, the one with the highest score is chosen even if the difference is minimal, and the students do not see the need to go one step further with both concepts to get a better decision basis. 3) Difficult to choose methodology: A student usually wants to follow a given checklist, but an important part of using a methodology is to adapt the methodology to the specific project, i.e. do conscious choices and use only parts of the list, or selected appropriate methods. 4) Motivation: It can be difficult to motivate the students for this type of subject, especially as some older students like to come with some experience from industry and business: "Does not happen like that in practice"! They want to skip the creative phase of specifying and developing different concepts and start directly with the "one and only" solution they first come up with. Mechatronics is multidisciplinary; It can be difficult to coordinate several supervisors with completely different backgrounds and different agendas. Internal cooperation is important. From this point of view a product development approach is suitable as a common framework for integration and cooperation. Different methods in different fields may be used within this common framework, and thus it supports cooperation. For feedback during lessons, the "one minute paper", an easy technique for student reflection has been used, as suggested by CDIO [4]. On a green note, students write down the most valuable thing they have learnt or are satisfied with, and one a red note they write down improvements, or things the did not see relevant or interesting. As typical in all product development, different users have different needs, trade-offs are necessary, and priorities need to be done. An example is the response on a question about sustainability as context in product development, which for one student were "inappropriate political focus in an engineering course", vs for another "very inspiring modern thinking". How to engage students who do not see sustainable thinking as a part of their education is also discussed in [11]. Engineering student's ability to reflect needs to be trained. The students do reflect on results, but often not connected to a specification, and reflection on process and teamwork is weak. 


\section{FURTHER COURSE DEVELOPMENT}

What could be done to improve such courses? To teach development of mechatronic products, it is well suited to apply a project based learning approach, cooperation in teams, digital tools and sustainability and product life-cycle as context. Constructive alignment, especially between the assignment within the courses, and the learning outcome requirements needs to be improved. The assignments today are described quite detailed as a specification for a prototype. This leaves little room for a life-cycle view and for the students to get training in specification and concept development based on the requirements, needs and wishes of different users in the product life cycle. This is important training for Bachelor and Master students. Scrum is one of the most popular agile frameworks used within software engineering, by software companies, successfully all over the world [8]. The Alpha Team Cards [8] is a tool to support scrum, with focus on stakeholders, requirements and for helping teams reflecting on the progress of the work and the team. These software engineering cards could be adapted to Mechatronics. It is anchored as an engineering tool, not as a "soft subject", which might make it suitable to encourage the teams to reflect, both on process, results and the team's performance. Adapted to Mechatronics, the tool might also support the specification process in other areas than software development. Another digital tool introduced for project planning and execution, Trello, support cooperation. The tool was found useful by the students. A Trello board based on the product development approach could be introduced as a structured approach to mechatronic projects, and together with the Alpha Team Cards form as the structure for more specific tools from the different engineering fields. By a tailored approach, students can get support in a complex development process, and be lead trough important phases of work and dimensions of products.

\section{REFERENCES}

[1] Nou 2020: Fremtidige kompetansebehov iii - laering og kompetanse i alle ledd. 2020:2 (norwegian), https : / / www . regjeringen . no/no/dokumenter/nou-2020-2/id2689744/, Accessed: 2021-01-12.

[2] European union: Circular economy action plan-for a cleaner and more competitive europe (european commission), https : //ec . europa . eu/environment/circular-economy/pdf/new_ circular_economy_action_plan.pdf, Accessed: 2021-01-12.

[3] T. Stålhane, B. Deraas, and G. Sindre, "What competence do software companies want from university graduates?" Nordic Journal of STEM Education, vol. 4, no. 1, pp. 1-15, Sep. 2020. DOI: 10.5324/njsteme.v4i1.3296.

[4] J. Malmqvist, K. Edström, A. Rosén, R. Hugo, and D. Campbell, "Optional cdio standards: Sustainable development, simulation-based mathematics, engineering entrepreneurship, internationalisation \&amp; mobility," in :, QC 20201103, vol. 1, 2020, pp. 48-59.

[5] J. Baird, T. N. Hopfenbeck, P. Newton, G. Stobart, and A. T. Steen-Utheim, "Assessment and learning: State of the field review," Oslo: Knowledge Centre for Education, 2014.

[6] J. B. Biggs, Teaching for quality learning at university: What the student does. Open university press, 2003.

[7] M. M. J. Sondre Sanden Tørdal Andreas Klausen, "Case study: Employing agile tools in teaching product development in mechatronics (abstract sent to the mnt-conference)," 2021.

[8] I. Jacobson, H. "Lawson, P.-W. Ng, P. E. McMahon, and M. Goedicke, The Essentials of Modern Software Engineering: Free the Practices from the Method Prisons! Association for Computing Machinery, Aug. 2019. DOI: 10.1145/3277669.

[9] T. Olsson and T. Roxå, "Pedagogical competence - a model promoting conceptual change in higher education," 2013.

[10] T. C. McAloone and D. C. Pigosso, "From ecodesign to sustainable product/service-systems: A journey through research contributions over recent decades," in Sustainable Manufacturing, Springer, Cham, 2017, pp. 99-111.

[11] M. Jakobsen and M. Ernzer, "How to get sustainable thinking into the students head," in Proceedings of the International Conference on Engineering Design (ICED), Glasgow, 2001. 